\title{
TEMPORAL LOBE (TL) DAMAGE FOLLOWING SURGERY AND HIGH-DOSE PHOTON AND PROTON IRRADIATION IN 96 PATIENTS AFFECTED BY CHORDOMAS AND CHONDROSARCOMAS OF THE BASE OF THE SKULL
}

\author{
Riccardo Santoni, M.D.,* Norbert Liebsch, M.D., Ph.D.,* Dianne M. Finkelstein, Ph.D., ${ }^{\dagger}$ \\ Eugen Hug, M.D., $*$ Patrick Hanssens, M.D., ${ }^{\ddagger}$ Michael Goitein, Ph.D., ${ }^{*}$ \\ Alfred R. Smith, Ph.D.,* Desmond O’Farrell,* Jimmy T. Efird, M.Sc., * \\ Barbara Fullerton, Ph.D. ${ }^{\S}$ and John E. Munzenrider, M.D.* \\ *Department of Radiation Oncology, Massachusetts General Hospital, Boston, MA 02114; ${ }^{\dagger}$ Massachusetts General Hospital and \\ Harvard School of Public Health, Boston, MA 02114; ${ }^{*}$ Radiation Oncology, Daniel den Hoed Cancer Centre, Rotterdam, The \\ Netherlands; and ${ }^{\S}$ Department of Otolaryngology, Massachusetts Eye and Ear Infirmary, Boston, MA 02114
}

Purpose: To determine the temporal lobe (TL) damage rate in 96 patients treated with high-dose proton and photon irradiation for chordomas and chondrosarcomas of the base of the skull.

Methods and Materials: The records of 96 consecutive patients treated at Massachusetts General Hospital

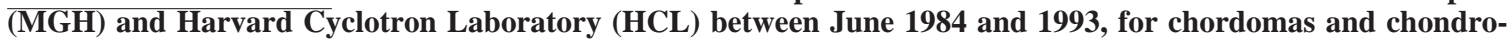
sarcomas of the base of the skull were reviewed. All the patients had undergone some degree of resection of the tumor prior to radiation therapy. Seventy-five patients were classified as "primary tumors" and 21 as recurrent or regrowing tumors after one or more surgical procedures. All the patients were randomized to receive 66.6 or 72 cobalt Gray equivalent (CGE) on a prospective dose-searching study by proton and photon irradiation (Radiation Therapy Oncology Group \#85-26) with conventional fractionation (1.8 CGE/day, 5 fractions/week). All treatments were planned using the three-dimensional (3D) planning system developed at the Massachusetts General Hospital, and the dose was delivered using opposed lateral fields for the photon component and a noncoplanar isocentric technique for the proton component. Clinical symptoms of TL damage were classified into 4 grades. Computerized tomography (CT) and magnetic resonance imaging (MRI) scans were evaluated for white matter changes. Abnormalities associated with persistent or recurrent tumor were distinguished from radiation-induced changes. TLs were delineated on the original scans of the 10 patients with damage and those of a group of 33 patients with no clinical or MRI evidence of injury. Dose distributions were calculated and dose-volume histograms were obtained for these patients.

Results: Of the patients, 10 developed TL damage, with bilateral injury in 2 and unilateral injury in 8 . The cumulative TL damage incidence at 2 and 5 years was 7.6 and 13.2\%, respectively. The MRI areas suggestive of TL damage were always separated from the tumor bed. Symptoms were severe to moderate in 8 patients. Several baseline factors, tumor- or host-related, were analyzed to evaluate their predictivity for TL damage: age, gender, tumor site, histology, type of presentation, type and number of surgical procedures, primary tumor volume, prescribed dose, normal tissue involvement, and volume of TL receiving doses ranging between 10 and 50 CGE or more. Only gender, in a univariate analysis (log rank) was a significant predictor of damage $(0.0155)$, with male patients being at significantly higher risk of TL injury. In a stepwise Cox regression that included gender as a variable, no other baseline variable improved the prediction of damage.

Conclusions: The 2- and 5-year cumulative TL damage rates were 7.6 and $\mathbf{1 3 . 2 \%}$, respectively. Despite the different TL damage rates related to age, tumor volume, number of surgical procedures prior to radiation therapy, and prescribed doses to the tumor, only gender was a significant predictor of damage $(p=0.0155)$ using a univariate (log rank) test. Chordomas and chondrosarcomas of the base of the skull may represent an interesting model to evaluate the TL damage rates because of their extradural origin, displacing the white matter instead of infiltrating it as gliomas do, because of their longer local recurrence-free survival other than gliomas and other brain tumors and because of the high doses of irradiation delivered to the target volume to obtain local control. (c) 1998 Elsevier Science Inc.

High-dose fractionated radiation, Skull base tumors, Central-nervous-system tolerance, Late radiation effects, Proton therapy, 3D treatment planning.

\section{INTRODUCTION}

The physical properties of the proton beam that make it attractive for radiation therapy are represented by their finite range in tissues due to the Bragg peak and sharply defined lateral beam edges. These features provide the basis for proton dose distributions that are superior to those obtainable with photons in many tumor to healthy tissue relation- 
ships, particularly at the base of the skull. The dose delivered to a tumor using protons can, consequently, be increased to a certain extent, with proton beam therapy (PBT), relative to that which can be delivered with photon therapy while maintaining a comparable rate of treatmentrelated morbidity. This difference in volume of healthy tissues included in comparison to photons is primarily due to minimal dose beyond the target due to the Bragg peak of the proton radiation.

Chordomas and chondrosarcomas of the base of the skull present a worthy challenge to the neurosurgeon and the radiation oncologist and are judged to be a good example of tumors that may likely benefit from high-dose proton radiation. With photon radiation therapy, only moderate doses of radiation can be delivered to the primary target, and most of these patients die with locally progressive disease (1). The total dose that can safely be delivered to the tumor is limited by the close proximity of healthy structures, such as the brain stem, temporal lobes, and optic chiasm and nerves. As a consequence of these particular tumor-healthy tissue relationships, and of the vital importance of the nervous structures, clinicians limit the radiation dose to levels tolerated by these structures (although the dose-response relationship for the central nervous system (CNS) has not yet been completely assessed) (2). Irradiation of the CNS can, in fact, produce a wide range of clinically expressed, as well as silent, injuries in the brain (3-5), which have been described in patients receiving doses in excess of 45 Gy (6).

Identification of radiation damage as a distinct entity from the effects of the tumor growth, surgical procedures, or other incidental pathologies is crucial to devise new protocols for dose-escalation studies, and to evaluate retrospectively the cost-benefit of the clinical achievements. The knowledge of the tolerance dose of the healthy tissues is essential to maximize the dose prescribed to the targets and, thereby, achieve the highest tumor control with a low probability of damaging healthy surrounding tissues.

To contribute to the comprehension of CNS late effects, after high-dose irradiation, we report our experience based on an analysis of 96 consecutive patients affected by chordomas or chondrosarcomas of the base of the skull who were treated with high-dose proton and photon irradiation and were randomized to receive 66.6 or 72 CGE on a controlled, prospective dose-searching study. The aim of the present study was to examine the correlation between clinical and imaging signs of temporal lobe damage and dose, features of the tumor, distortion of the normal anatomy induced by the tumor, number of surgical procedures, and other host characteristics.

\section{METHODS AND MATERIALS}

Ninety-six consecutive patients with chordomas and chondrosarcomas of the base of the skull were randomized to receive 66.6 or $72 \mathrm{CGE}$ in a prospective dose-searching study (RTOG-Radiation Therapy Oncology Group \#85-26) by proton and photon techniques at the Massachusetts Gen- eral Hospital (MGH) and Harvard Cyclotron Laboratory (HCL) between July 1984 and July 1993.

The patients ranged in age from 11 to 80 years, with a median of 44 years; there were 51 males and 45 females. Of the tumors, 41 were classified as arising from the occipital bone (OB), 26 from the sphenoid bone (SB), 28 from the temporal bone (TB), and one mainly involving the nasopharynx (NA). The histology of the tumors were 49 chordomas (17 of 49 chondroid chordomas (CC) and 32 of 49 nonchondroid chordomas NCC)) and 47 chondrosarcomas (28 of 47 intermediate-grade chondrosarcomas (IGCS) and 19 of 47 low-grade chondrosarcomas (LGCS)). All histological diagnoses were confirmed by the Sarcoma Section of the Massachusetts General Hospital Pathology Department.

All the patients had previously undergone biopsy or subtotal removal of the tumor. The type of surgical approaches have been classified as craniotomy-type or noncraniotomytype, including in the latter category the transsphenoidal, transoral, transpalatine, or lateral rhinotomy techniques.

Of the patients, 75 were treated for a primary tumor, having been referred for radiation therapy immediately after one or more debulking surgeries; 21 underwent treatment for persistent and/or recurrent tumors with a median and mean time, between surgery and irradiation, of 26 and 44 months, respectively.

Only one surgical procedure was performed in 64 patients; 32 patients underwent more than one surgery and more than $50 \%$ of these (18 of 32) were performed in the group of 21 patients with persistent and/or recurrent tumors (Table 1).

The treatments were delivered as $1.8 \mathrm{CGE} /$ fraction with 5 fractions a week. The proton dose is reported in CGE, which is the physical dose times the relative biological effectiveness of protons, relative to ${ }^{60}$ cobalt, of 1.10 (7). Many experimental determinations of RBE have been made, using cell cultures and in animals, and have yielded a range $(0.78-1.32)$ of RBEs for protons $(7,8)$. The value of 1.10 was selected from early experiments, has been used since the beginning of the clinical treatments at HCL-MGH, and seems to be consistent with the clinical response of patients.

The Harvard Cyclotron is available only 4 times a week and the total dose was delivered with 4 proton fractions a week and one photon fraction (10 MeV X-rays from a linear accelerator). The delivered total dose to the primary target volume ranged between 64.8 and 72 CGE (median dose 68.4). The proton contribution to the total dose ranged between 30.6 and 66.2 CGE. One patient only received a low proton dose (30.6 CGE) and the median and average proton doses were 55.8 and 55.3, respectively. The photon contribution to the overall dose to the target volume ranged between 5.4 and $36 \mathrm{~Gy}$, with one patient only receiving 36 Gy with X-rays (median and average photon doses being 12.6 and 13.9 , respectively).

The treatment philosophy was to deliver the prescribed dose to as much as possible of the tumor while maintaining the brain stem, the spinal cord, and optic structures at or below dose constraints; the dose constraints of the healthy 
Table 1. Patient characteristics

\begin{tabular}{|c|c|}
\hline Characteristic & $n$ \\
\hline \multicolumn{2}{|l|}{ Age } \\
\hline$\leq 50$ & 64 \\
\hline$>50$ & 32 \\
\hline \multicolumn{2}{|l|}{ Gender } \\
\hline Male & 51 \\
\hline Female & 45 \\
\hline \multicolumn{2}{|l|}{ T-site } \\
\hline Occipital bone & 41 \\
\hline Sphenoid bone & 26 \\
\hline Temporal bone & 28 \\
\hline Nasopharynx & 1 \\
\hline \multicolumn{2}{|l|}{ Histology } \\
\hline Chondroid chordoma & 17 \\
\hline Nonchondroid chordoma & 32 \\
\hline Intermediate-grade chondrosarcoma & 28 \\
\hline Low-grade chondrosarcoma & 19 \\
\hline \multicolumn{2}{|l|}{ Type of presentation } \\
\hline Primary tumor & 75 \\
\hline Persistent and or recurrent tumor & 21 \\
\hline \multicolumn{2}{|l|}{ Number of surgical procedures } \\
\hline 1 Surgery & 64 \\
\hline$>1$ Surgery & 32 \\
\hline \multicolumn{2}{|l|}{ Type of surgical procedure } \\
\hline Craniotomy & 58 \\
\hline Noncraniotomy & 38 \\
\hline \multicolumn{2}{|l|}{ Primary target volume } \\
\hline$<70 \mathrm{cc}$ & 83 \\
\hline$\geq 70 \mathrm{cc}$ & 13 \\
\hline \multicolumn{2}{|c|}{ Prescribed dose (CGE) to the target volume } \\
\hline 66.6 & 44 \\
\hline 72 & 52 \\
\hline
\end{tabular}

tissues, surrounding the tumors, were lower than the prescribed doses to the target volume. A lower than prescribed dose was, consequently, delivered to small portions of the tumor encroaching into the brain stem or abutting the optic chiasm or optic nerves so that the doses to these structures would not exceed the following values: $\leq 64$ CGE, $\leq 53$ CGE, $\leq 48$ CGE to the surface of the spinal cord or brainstem, to the center of the spinal cord or brain stem, and to the point on the spinal cord or brain-stem surface opposite the point receiving the highest doses, and $\leq 60 \mathrm{CGE}$ to the optic chiasm and both optic nerves. In cases where tumor abutted one optic nerve, and vision in the contralateral eye was good, that optic nerve could get $\leq 64$ CGE.

Overall treatment time ranged between 50 and 71 days (median and mean values 55 and 55.3 days, respectively), with a total number of fractions ranging between 37 and 40 . Primary volumes ranged between 5 and $135 \mathrm{cc}$ with a median and average volume of 40 and $43.2 \mathrm{cc}$, respectively. Patient characteristics are summarized in Table 1.

All the treatments were planned using the 3D treatmentplanning system developed at Massachusetts General Hospital $(\mathrm{MGH})(9,10)$. With the patient immobilized in the treatment position, 3-mm thick contiguous CT scan sections were obtained. All the volumes of interest (primary and secondary targets, brain stem, optic chiasm and nerves, and temporal lobes) were delineated on the CT scans using all the available information (radiographic, MRI, and CT studies, clinical data, and operative findings). Multiple treatment fields were designed for each patient, individualizing the treatment technique so as to minimize dose to the normal structures and deliver the prescribed dose to as much as possible of the primary target volume. Brass apertures were used to shape the edges of the fields and lucite compensators were used to shape the distal edge of the beam, to ensure adequate tumor coverage $(11,12)$. Before treatment, patient position relative to the beam center and aperture edges was verified radiographically by comparing diagnostic X-ray portal film and a digital reconstructed radiograph derived from the CT data. Day-to-day reproducibility was within \pm $2 \mathrm{~mm}$ (13).

Patient follow-up has continued from 18 to 126 months, with a median and mean follow-up time of 41 and 43.8 months, respectively. Follow-up examinations included a general physical and neurological examination every 6 months after treatment for the first 3 to 5 years, and then annually thereafter. CT and MRI scans of the brain and chest X-rays were generally obtained annually, or more frequently when clinically indicated.

To evaluate temporal lobe damage rate, all the available images and clinical documents of these patients have been reviewed.

The clinical symptoms, related to white matter changes in the temporal lobe as shown by the CT and MRI images, were classified into 4 grades according to the criteria reported in Table 2. Such a scoring system is a modification of the RTOG/EORTC Late Morbidity Scoring Scheme. CT and MRI abnormalities associated with persistent or recurrent tumor or changes induced in the normal tissues by surgery could be distinguished from white matter modifica-

Table 2. Neurologic toxicity criteria

\begin{tabular}{|c|c|c|}
\hline Mental status & Seizures & Motor function \\
\hline $\begin{array}{l}\text { Gr. 1: Mild subjective } \\
\text { memory loss or } \\
\text { transient alteration } \\
\text { of mental status }\end{array}$ & - & - \\
\hline $\begin{array}{l}\text { Gr. } 2 \text { : Moderate } \\
\text { subjective memory } \\
\text { loss or mental } \\
\text { disorder status } \\
\text { alteration } \\
\text { substantially } \\
\text { affecting function }\end{array}$ & $\begin{array}{r}\text { Transient } \\
\text { seizure }\end{array}$ & $\begin{array}{l}\text { Substantially affects } \\
\text { function: }<50 \% \\
\text { decrease of } \\
\text { baseline } \\
\text { capabilities }\end{array}$ \\
\hline $\begin{array}{l}\text { Gr. 3: Severe memory } \\
\text { loss affecting } \\
\text { function }<50 \% \text { of } \\
\text { time }\end{array}$ & $\begin{array}{l}\text { Seizure disorder } \\
\text { controlled by } \\
\text { medical } \\
\text { therapy }\end{array}$ & $\begin{array}{l}\text { Substantially affects } \\
\text { function: }>50 \% \\
\text { decrease of } \\
\text { baseline } \\
\text { capabilities }\end{array}$ \\
\hline Gr. 4: Coma & $\begin{array}{l}\text { Seizure disorder } \\
\text { not controlled } \\
\text { by medical } \\
\text { therapy }\end{array}$ & Paralysis \\
\hline
\end{tabular}

Modified RTOG-EORTC late morbidity scoring system. 
Table 3. Clinical features of 10 patients with TL damage

\begin{tabular}{|c|c|c|c|c|c|c|c|c|c|}
\hline \multirow[b]{2}{*}{ Patient } & \multirow[b]{2}{*}{ Gender } & \multirow[b]{2}{*}{ Age } & \multirow[b]{2}{*}{ Tumor site } & \multirow{2}{*}{$\begin{array}{c}\text { Type of } \\
\text { presentation }\end{array}$} & \multirow[b]{2}{*}{ Histology } & \multicolumn{2}{|l|}{ Surgery } & \multirow{2}{*}{$\begin{array}{l}\text { Tumor } \\
\text { volume } \\
\text { (cc) }\end{array}$} & \multirow{2}{*}{$\begin{array}{c}\text { Prescribed } \\
\text { dose } \\
(\mathrm{CGE})\end{array}$} \\
\hline & & & & & & Type & $n$ & & \\
\hline \multirow{2}{*}{1} & \multirow{2}{*}{ M } & \multirow{2}{*}{51} & \multirow{2}{*}{ OB } & \multirow{2}{*}{ Recurrent } & \multirow{2}{*}{$\mathrm{CC}$} & Infratemporal cr. & 1 & - & - \\
\hline & & & & & & Pterional cr. & 1 & - & - \\
\hline 2 & M & 61 & SB & Primary & $\mathrm{NCC}$ & Sublabial & 1 & 30 & 72 \\
\hline 5 & $\mathrm{~F}$ & 52 & SB & Primary & NCC & Transphenoidal & 1 & 8 & 66.6 \\
\hline \multirow[t]{2}{*}{6} & \multirow[t]{2}{*}{ M } & \multirow[t]{2}{*}{40} & \multirow[t]{2}{*}{ OB } & \multirow[t]{2}{*}{ Primary } & \multirow[t]{2}{*}{$\mathrm{NCC}$} & Suboccipital cr. & 1 & 29 & 66.6 \\
\hline & & & & & & Transnasal & 1 & - & - \\
\hline 7 & M & 22 & SB & Recurrent & LGCS & Pterional cr. & 2 & 46 & 72 \\
\hline 8 & M & 60 & OB & Primary & $\mathrm{NCC}$ & Transmaxillary & 1 & 113 & 66.6 \\
\hline 9 & M & 51 & SB & Primary & LGCS & Temporal cr. & 1 & 15 & 72 \\
\hline
\end{tabular}

$\mathrm{OB}=$ occipital bone; $\mathrm{SB}=$ sphenoid bone; $\mathrm{TB}=$ temporal bone; $\mathrm{CC}=$ chondroid chordoma; $\mathrm{NCC}=$ Nonchondroid chordoma; $\mathrm{IGCS}=$ intermediate-grade chondrosarcoma; LGCS = low-grade chondrosarcoma.

tions induced by the treatment that appeared during follow-up as areas separated from the site of the tumor bed.

Temporal lobes were outlined on the planning CT scans for all the patients with damage and for 33 patients selected among those without clinical and/or radiographic evidence of TL injury or of white matter changes, after radiation therapy. The Control Group was selected to match the patients with damage with respect to follow-up time, site, volume and histology of the tumor, and dose delivered to the target. A neuroanatomist (B. F.) determined volume using brain and skull landmarks visible on the CT and MRI scans. Using the MGH 3D treatment-planning system, the total volume of the temporal lobes were calculated, dosevolume histograms have been obtained, and the dose distributions have been recalculated.

The Kaplan-Meier product-limit method was used to estimate probability of freedom from temporal lobe damage, with statistical inferences on actuarial curves made by using the log rank test. The Cox proportional-hazards regression model was used to assess the simultaneous effect of several baseline parameters on the risk of temporal lobe damage. All baseline variables were dichotomized for this analysis.

\section{RESULTS}

The 2- and 5-year cumulative TL damage rates were 7.6 and $13.2 \%$, respectively (standard errors 2.8 and 4.1, respectively). Ten patients with TL damage were identified, 1 with MRI white matter changes only, and 9 with both MRI changes and clinically evident TL injury. One had Grade 2 and 8 had Grade 3 injury. One patient developed multiple Grade 2 symptoms and 7 suffered Grade 3 symptoms (4 of 7 one Grade 3 only, 2 of 7 multiple Grade 3, and 1 of 7 Grade 3 and 2). Epilepsy and deterioration of the mental status with impairment of short- or long-term memory were associated in 3 patients. The clinical features of the 10 patients with TL damage are repeated in Table 3. Severity of the clinical symptoms in 9 of 10 patients with TL damage is reported in Table 4.

Two patients showed bilateral TL damage and, in 8, 1 temporal lobe showed postirradiation changes. Five patients with unilateral damage presented with tumor located in the center of the base of the skull and, in 3, the disease had grown to the temporal lobe. In 3 patients, the damage was ipsilateral to tumor side. The 2 patients with bilateral TL damage presented a centrally located tumor in 1 case and a prevalently lateral tumor in the other one. Three patients were reoperated to resect the injured area in the temporal lobe and, in all of them, radionecrosis was pathologically documented.

White matter in the temporal lobes was always characterized, on the MRI scans, by a generalized increase in the signal intensity on T2-weighted images and was located in the anterior portion of the TL extending medially and posteriorly. Figures 1A, B and 2 show two examples of TL damage in 2 patients with unilateral (Fig. 1) and bilateral (Fig. 2) lesions, respectively.

The present status of the 10 patients with TL damage is reported in Table 5. Seven patients showed improvement

Table 4. Clinical symptoms at the diagnosis of TL damage

\begin{tabular}{rrrrr}
\hline & \multicolumn{5}{c}{ Grade (clinical symptoms) } \\
\cline { 2 - 5 } Patient & Headache & Motor function & Seizures & Mental status \\
\hline 1 & - & 2 & 2 & 2 \\
2 & - & - & 3 & 2 \\
3 & 1 & - & - & - \\
4 & - & - & 3 & - \\
5 & - & - & 3 & 3 \\
6 & - & - & 3 & 3 \\
7 & - & - & - & 3 \\
9 & - & - & - & - \\
10 & 3 & & - & - \\
\hline
\end{tabular}




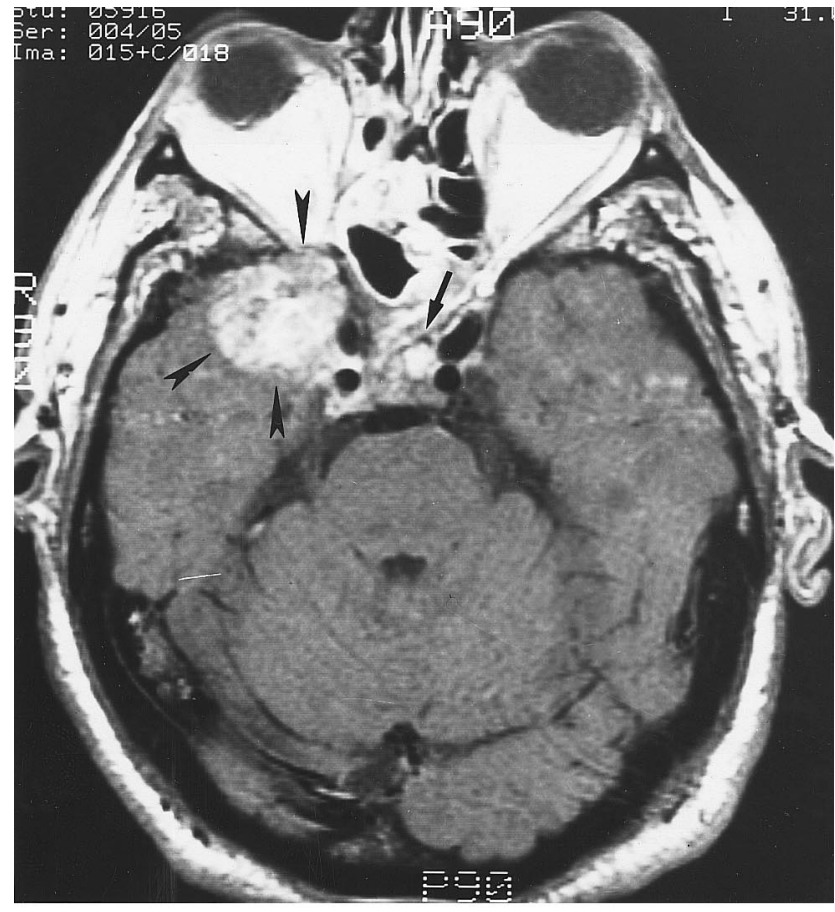

A

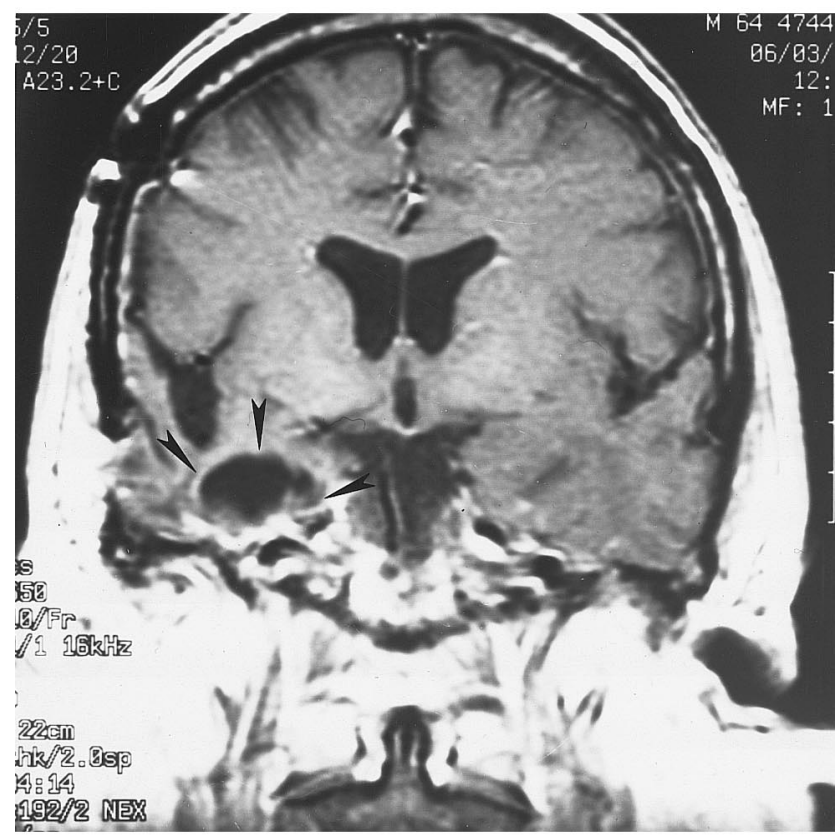

B

Fig. 1. MRI changes induced in the TL after high-dose photon and proton irradiation for base of the skull tumors in a patient with unilateral TL damage, which is visible as (A) an oval-shaped area of increased signal separated by the tumor bed. The black arrowheads indicate the TL damage area and black arrows the upper portion of the tumor site. (B) shows the MRI appearance of the right temporal lobe after surgery to resect the damaged area (black arrowheads). Pathology of the resected brain tissue demonstrates the presence of necrosis.

after medical or surgical treatment; 1 (Patient 3 of Table 5) experienced a local recurrence 1 year after the diagnosis of TL damage and died of locally progressive disease after 30

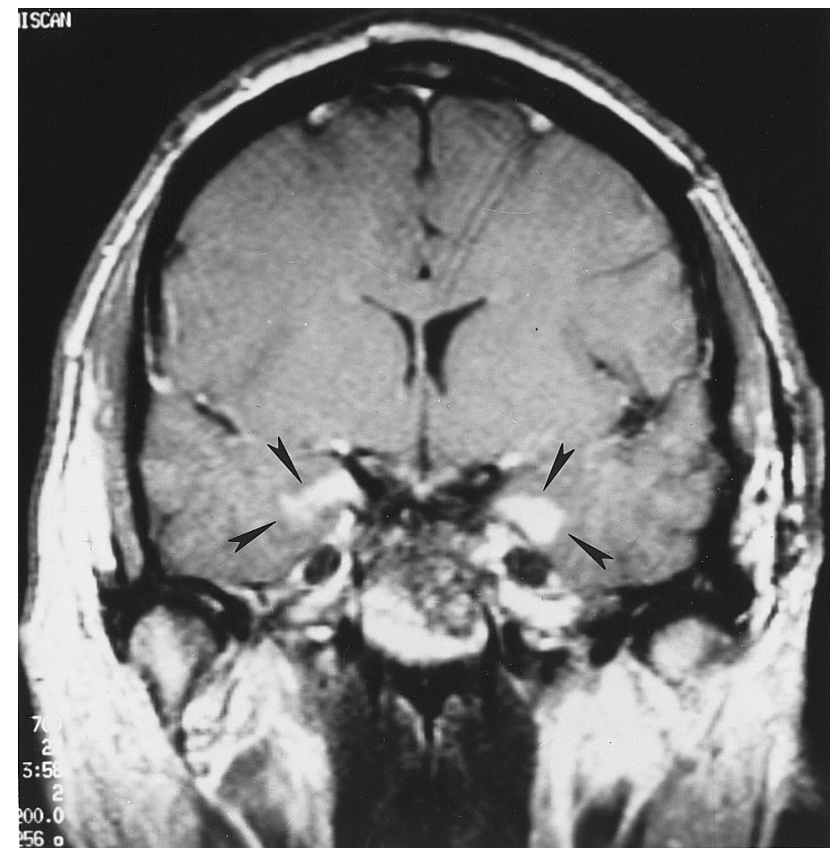

Fig. 2. Bilateral temporal lobe damage represented by two, almost symmetrical, irregularly shaped areas of increased signal (black arrowheads) on the inner aspect of both of the temporal lobes.

months. One patient was clinically stable, but recurrent tumor was diagnosed 9 months after onset of damage to the right temporal lobe (Patient 8 of Table 5). Two patients (Number 7 and 9 of Table 5) whose symptoms were not controlled by the medical treatment experienced progressive symptoms without evidence of regrowing tumor.

The following clinical and pathologic factors were evaluated to determine if they were associated with TL damage of any grade: age, gender, tumor site, histology, type of presentation, type and number of surgical procedures, pri-

Table 5. Status of the patients and evolution of the symptoms after treatment of the TL damage

\begin{tabular}{|c|c|c|}
\hline Patient & Clinical symptoms & Status* \\
\hline 1 & $\begin{array}{l}\text { Partial improvement after surgical resection; } \\
\text { persistent loss of memory }\end{array}$ & A.P.R. \\
\hline 2 & Complete recovery after surgical resection & A.C.R. \\
\hline 3 & $\begin{array}{l}\text { Improved after surgical resection; local } \\
\text { recurrence; dead local disease }\end{array}$ & D.D. \\
\hline 4 & Complete control of seizures & A.C.R. \\
\hline 5 & Deteriorated mental condition & A.C.R. \\
\hline 6 & $\begin{array}{l}\text { Complete control of seizures; persistent } \\
\text { memory impairement }\end{array}$ & A.P.R. \\
\hline 7 & Increasing memory loss & A.S.E. \\
\hline 8 & $\begin{array}{l}\text { Initially asymptomatic; local recurrence; } \\
\text { cerebral infarction }\end{array}$ & A.D. \\
\hline 9 & Increasing memory loss & A.S.E. \\
\hline 10 & Complete control of seizures & A.C.R. \\
\hline
\end{tabular}

* A.C.R. = Alive with complete recovery; A.P.R. = alive with partial recovery; A.S.E. = alive with side effects; A.D. = alive with local progressive disease; D.D. = dead with local progressive disease. 
Table 6. TL damage and clinical- and tumor-related parameters

\begin{tabular}{|c|c|c|}
\hline Variable & $\begin{array}{c}\text { Patients with } \\
\text { damage }(\%)\end{array}$ & $p$ value \\
\hline \multicolumn{3}{|l|}{ Age } \\
\hline$\leq 50$ & 3 of $64(5 \%)$ & \\
\hline$>50$ & 7 of $32(22 \%)$ & 0.191 \\
\hline \multicolumn{3}{|l|}{ Gender } \\
\hline Males & 9 of $51(18 \%)$ & \\
\hline Females & 1 of $45(2 \%)$ & 0.0155 \\
\hline \multicolumn{3}{|l|}{ Tumor site } \\
\hline $\mathrm{OB}$ & 4 of $41(10 \%)$ & \\
\hline SB & 4 of $26(15 \%)$ & 0.437 \\
\hline TB & 2 of $28(7 \%)$ & \\
\hline \multicolumn{3}{|l|}{ Histology } \\
\hline $\mathrm{CC}$ & 1 of $17(6 \%)$ & \\
\hline NCC & 5 of $32(16 \%)$ & \\
\hline IGCS & 2 of $28(7 \%)$ & 0.619 \\
\hline LGCS & 2 of $19(10 \%)$ & \\
\hline \multicolumn{3}{|l|}{ Type of presentation } \\
\hline Primary t. & 7 of $75(9 \%)$ & \\
\hline Recurrent t. & 3 of $21(14 \%)$ & 0.513 \\
\hline \multicolumn{3}{|l|}{ Tumor volume } \\
\hline$\geq 70 \mathrm{cc}$ & 4 of $13(31 \%)$ & \\
\hline$<70 \mathrm{cc}$ & 6 of $83(7 \%)$ & 0.391 \\
\hline \multicolumn{3}{|c|}{ Intracranial arteries involvement* } \\
\hline Absent & 4 of $43(9 \%)$ & \\
\hline 1 artery & 2 of $35(11 \%)$ & 0.689 \\
\hline$>1$ artery & 4 of $18(11 \%)$ & \\
\hline \multicolumn{3}{|c|}{ Number of surgical procedures } \\
\hline 1 & 5 of $64(8 \%)$ & \\
\hline$>1$ & 5 of $32(16 \%)$ & 0.189 \\
\hline \multicolumn{3}{|l|}{ Type of surgery } \\
\hline at least 1 craniotomy & 6 of $58(10 \%)$ & \\
\hline Noncraniotomy & 4 of $38(10 \%)$ & 0.980 \\
\hline \multicolumn{3}{|l|}{ Prescribed dose $e^{\dagger}$} \\
\hline 66.6 CGE & 3 of $44(7 \%)$ & \\
\hline 72 CGE & 7 of $52(13 \%)$ & 0.304 \\
\hline
\end{tabular}

mary volume tumor, prescribed dose, normal tissue involvement by the tumor prior to radiation therapy, and volume of temporal lobe receiving escalating doses. Table 6 reports the TL damage rates with respect to the examined clinical and pathologic parameters. A tendency to a higher rate of temporal lobe damage was indicated for the older patients $(5 \%$ vs. $22 \%$, respectively, for the age groups $\leq 50$ and $>50$ years old), the male sex (18\% vs. $2 \%$, respectively, for males and females), primary tumor volume greater than 70 cc ( $7 \%$ vs. $31 \%$, respectively, for the tumor volumes $<70$ and $\geq 70 \mathrm{cc}$ ), more than one surgical procedure ( $8 \%$ vs. $16 \%$, respectively, for only one or more than one surgical procedure), and higher radiation doses (7\% vs. $13 \%$ for the 66.6 and 72 CGE groups, respectively). In addition to the temporal lobe damage rate, the significance of each for predicting damage from a univariate (log rank) test, are reported. Only gender was a significant predictor of damage $(p=0.0155)$. In a stepwise Cox regression, which included gender as a variable, no other baseline variable significantly improved the prediction of TL damage.

No statistically significant difference was found when the average volumes of temporal lobes receiving increasing doses in the patients expressing damage, were compared with the average volumes of temporal lobes receiving those doses in patients without damage (Table 7).

As an example, we report here the short summaries of the clinical histories of 2 of the 10 patients with TL damage, who may be considered representative of the entire group.

\section{Patient A (\#1 of Table 5).}

Patient 1 is a black 51-year-old man with a history of headache and diplopia since the age of 15 . At the end of 1990, he noticed the onset of facial numbness, ipsilateral diplopia, and ptosis on the right side. CT and MRI scans demonstrated a $6 \times 6 \mathrm{~cm}$ right parasellar tumor with extension into the sphenoid sinus, sella, right prepontine cisterns, and infratemporal and temporal fossa encasing the right internal carotid artery. Following a sublabial transsphenoidal biopsy that established the diagnosis of chordoma, a partial tumor resection via an infratemporal fossa approach, and a transfacial, transsphenoidal approach in 2 separate procedures for further debulking of the tumor were accomplished. Fifteen months later, progressive decrease of vision in the right eye was treated with a fourth surgical approach via a right pterional craniotomy, to decompress the right optic nerve. Following that surgery, the vision recovered completely, but postoperative MRI showed a large residual right parasellar mass that compressed and displaced adjacent temporal lobe. The right middle cerebral artery was encased by the tumor. The patient was treated from October through December 1992. Two opposed lateral fields were treated with $10-\mathrm{MeV} \mathrm{X}$-rays, and multiple noncoplanar, isocentric proton portals were employed, delivering $72 \mathrm{CGE}$ in 40 fractions to the primary target volume.

In November 1993, the patient developed loss of memory and energy, dysarthria, ataxia, and dysmetria. An MRI was obtained showing the presence of an abnormal increased T2 signal in the right anterior temporal lobe. In December 1993, he underwent surgery to remove necrotic brain tissue from the right middle fossa. Postoperatively, the patient's symptoms partially recovered, but with persistent loss of memory and decreased energy.

Dose-volume histograms of the temporal lobes are shown in Fig. 3. Review of the dose distribution showed a

Table 7. Volumes of $78 \mathrm{TL}$ receiving escalating doses

\begin{tabular}{cccc}
\hline & \multicolumn{2}{c}{ Average volume of TL in cc } & \\
\cline { 2 - 3 } Dose (CGE) & $\begin{array}{c}\text { No TL damage } \\
(66 \text { of } 78)\end{array}$ & $\begin{array}{c}\text { TL damage } \\
(12 \text { of } 78)\end{array}$ & $p$ value \\
\hline$\geq 10$ & 46.3 & 51.6 & 0.429 \\
$\geq 20$ & 34.7 & 43.0 & 0.142 \\
$\geq 30$ & 21.1 & 29.1 & 0.051 \\
$\geq 40$ & 12.8 & 16.6 & 0.385 \\
$\geq 50$ & 8.0 & 11.8 & 0.330 \\
\hline
\end{tabular}

* Comparison between TL with damage (12 of 10 patients) and the Control Group (66 outlined TL in 33 control patients). 


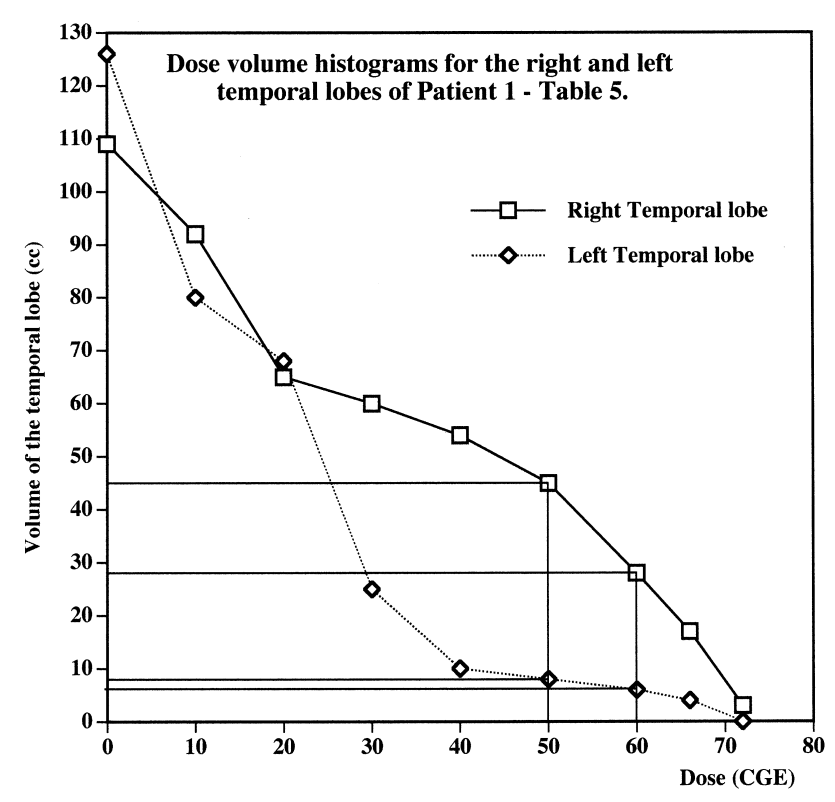

Fig. 3. Dose-volume histograms for the temporal lobes of Patient 1 of Table 5. The review of the dose distribution demonstrated a higher dose in the medial portion of the temporal lobe immediately adjacent to the tumor.

uniform dose throughout the right temporal lobe, with the doses being greatest in its medial portion immediately adjacent to the tumor.

\section{Patient B (\#5 of Table 5)}

Patient 5, a white 52-year-old woman, developed diplopia on right lateral gaze and headache in November 1986. A CT scan showed a sellar mass. The patient had hypopituitarism since age 20, and had stopped taking her thyroid hormonal medication at some point prior to presentation. TSH levels were elevated, and no further investigation was undertaken. The diplopia resolved, but recurred in October 1987, and MRI showed a right parasellar and sphenoidal mass. The tumor had invaded the sphenoid sinus and displaced the cavernous sinus. Biopsy was obtained, revealing a chordoma. Postoperatively, diplopia was intermittent; she was treated from February through April 1988. The photon component was given through two opposed lateral fields. A multiple-field approach, using a noncoplanar isocentric technique, was used for the proton component of the irradiation to deliver the total dose of $66.6 \mathrm{CGE}$ to the primary target volume $(8 \mathrm{cc})$ in 37 fractions.

In May 1991, the patient experienced the onset of temporal lobe seizures with frequent episodes of panic attacks and abnormal feelings. An MRI showed the presence of abnormal T2 enhancing area in the medial aspect of the right temporal lobe, consistent with temporal lobe damage. She was started on medications (divalproex [Depakote ${ }^{\circledR}$ ] $250 \mathrm{mg}$ q.i.d.), after which she experienced complete control of the seizures.

\section{Management of TL damage}

The development of TL necrosis following irradiation usually produces moderate to severe symptoms that may be relieved with corticosteroids and/or anticonvulsants. When steroids cannot be tapered, undesirable side effects may occur. An alternative to medical treatment is reoperation and evacuation of the necrotic area. In these patients, recovery after surgery was complete in 1 patient and partial in a second, who experienced persistent memory loss. A third patient, on the contrary, remained stable after surgical resection with persistent headache; he experienced a local recurrence and died with progressive local disease.

\section{DISCUSSION}

The classical late adverse effect of therapeutic or incidental brain irradiation is localized necrotic reaction, which occurs typically at a few months to several years after irradiation and is usually associated with neurological symptoms that cannot be attributed to recurrent tumor (14).

After high-dose radiation therapy, "the specific endpoint chosen for complication of the brain is radionecrosis" (2). Burger et al. (15) provided a clear description of the histological modifications associated with radiation necrosis in brains irradiated for gliomas. Coagulation necrosis, vascular thickening, perivascular fibrosis, calcium and fibrin deposition, petechiae, and chronic inflammatory cell infiltrates are combined in varying degrees and must be distinguished from necrotic changes within the tumor.

The pathogenesis of radionecrosis has not yet been completely defined. Different hypotheses that have been advanced are not mutually exclusive. The vascular hypothesis (16-21) suggests that the major injury is borne by smalland medium-size vessels and that necrosis is secondary to ischemia. According to the glial theory $(22,23)$, irradiation damages glial cells, particularly the oligodendroglial cells, leading to white matter cavitation and demyelination. The immunological hypothesis (24) attributes radiation necrosis and vascular changes to a response to antigens released from damaged glial cells.

Radiation necrosis rates, following treatment with megavoltage irradiation, are not well defined and there is a need for more information about the tolerance of healthy tissue to irradiation, the dose-time relationship (25), and the partial volumes of healthy tissues receiving variable dose levels (26). Changes following cranial irradiation have been identified among survivors of primary CNS tumors and acute lymphoblastic leukemia, although necrosis following irradiation for extracranial tumors has been described (5).

Burger et al. reported 4 cases of radiation necrosis among 17 patients dying with malignant gliomas treated with doses between 50 and 60 Gy (15). Prevalence of this condition in autopsied patients does not define the incidence of radionecrosis among living patients.

Sheline et al. (5) found in the literature 80 cases of brain necrosis where irradiation was "either the causative agent or a major contributing factor." A majority of these patients 
had tumors other than gliomas (32 gliomas vs. 48 head and neck, skin, and pituitary tumors). Twenty patients received doses of 50 Gy or less with nonconventional fractionation (2.5 Gy/fraction) and, in 26, the total dose was $>70$ Gy or MRE (Megavolt rad equivalent).

Marks et al. (6) reported that 7 (5\%) of 139 patients with brain or pituitary tumors who received $>45$ Gy in $1.8-2.0$ Gy fractionation, developed pathologically demonstrable cerebral radionecrosis. Necrosis was documented by autopsy in 4 , at reoperation in 2 , and after needle biopsy in 1 , and it was located distant from the tumor in 3, adjacent to the tumor in 2, and within the tumor bed in 2 .

Lee et al. (27) reported on 102 patients with clinical and CT scan diagnosis of late TL necrosis after radical radiation therapy for nasopharyngeal carcinoma among 9606 patients. Although their report is mainly based on the correlation of clinical and CT signs, 11 of the 102 reported patients had pathology confirmation ( 3 by biopsy and 9 by autopsy) of the brain damage; the areas of maximum damage were found in the white matter within the irradiated volume.

CT scans demonstrate several abnormalities in patients with CNS radiation necrosis: regions of hypodensity in white matter, atrophy and areas of frank necrosis $(4,28)$. MRI has shown a greater sensitivity to identify these abnormalities (29-32) due to alterations in water content that accompanies such changes and appear bright on T2weighted sequences. Constine et al. (29) performed a correlation between neurological symptoms and MRI findings in patients treated for gliomas. They demonstrated that MRI was superior to $\mathrm{CT}$ in detecting postradiation abnormalities in the irradiated brain, and in making correlations between clinical signs and imaging abnormalities. A pattern of increasing severity of MRI changes was established with four phases documented: Grade I = periventricular whitening or intensity; Grade II = focal extension of intense signal into the white matter; Grade III = diffuse extension into white matter; Grade IV = diffuse coalescence of white and grey matter into intense signal region, loss of architecture, cortical atrophy, and hydrocephalus ex vасио. The authors correlated clinical symptoms to MRI grade changes. Seven patients had Grade III-IV MRI changes; five of these presented mental impairment and two were asymptomatic. Such clinical problems developed as long as 7 years after irradiation, but generally became apparent within 2 years. Clinical symptoms were correlated to changes in MRI grade. The incidence of Grade 3 and 4 changes in the white matter was significantly higher in the patients receiving whole-brain radiation relative to those receiving local-field irradiation only (Grade 3 to 4 changes in 50\% and 14\%, respectively).

The analysis of the data from the literature allows the conclusions that (a) Pathology of the brain damage has been clearly defined; (b) pathologic confirmed cases of brain necrosis may occur in patients receiving doses in excess of $45 \mathrm{~Gy}$; but (c) it may be difficult to differentiate treatmentrelated necrosis from tumor progression in patients with malignant gliomas, the most frequent disease for which high-dose brain irradiation is used; and (d) correlation between neurological and MRI changes may demonstrate a rate of late effects as high as $12 \%$ (29).

The incidence of radionecrosis is probably underestimated in the glioma series because patients die early and the autopsy rate is low. In pathology series, such as that of Burger et al. (15), radionecrosis may, on the contrary, be overestimated because patients may be referred specifically because of brain damage following radiation therapy, resulting in selection bias.

To our knowledge, no data are available in the literature about the incidence of white matter necrosis after protonbased irradiation for intracranial or extracranial tumors. Urie et al. (33) performed a very detailed analysis of the normal anatomy, dose distribution, and clinical outcomes of 27 patients treated with protons for skull base tumors, and found 5 patients with neurological symptoms that were attributed to radiation injury. They analyzed 594 CNS structures (22 structures per patient in 27 patients), and found 17 structures with clinically manifest radiation injury and concluded that "for dose fractionation of 1.8-2.0 CGE, the probability of radiation injury is 5\% at 70 CGE (64-81 CGE with 95\% confidence)."

Debus et al. (34) analyzed the incidence of brain stem toxicity in a group of 282 patients treated for chordomas and chondrosarcomas of the base of the skull treated with combined megavoltage photon and $160 \mathrm{-MeV}$ proton radiotherapy (prescribed doses to the target volume ranging between 63 and 79.2 CGE). They report brain stem symptoms, attributable to the treatment, in 17 patients $(6 \%)$, resulting in death in 3 of them. They suggest that the tolerance of the brain stem to the fractionated radiotherapy appears to depend on the volume of tissue included in the high-dose regions, and that an increased risk of brain stem toxicity was significantly associated with maximum brain stem dose, volume receiving $>50 \mathrm{CGE},>55 \mathrm{CGE}$, and >60 CGE, number of surgical procedures, and prevalence of diabetes mellitus or high blood pressure. Presumably the cause of death in 3 patients of the 17 reported with brain stem symptoms may be attributable to brain stem necrosis, but this is not clearly stated.

Liu et al. (35) tried to determine the incidence of myelopathy after high-dose proton and photon radiotherapy to the cervical spine, for primary or recurrent chordomas and chondrosarcomas receiving doses ranging between 64.5 and 79.2 CGE. They report that 4 (5.1\%) of 78 patients developed high-grade (RTOG Grade 3 and 4) late toxicity, with 3 patients experiencing sensory deficit, but no motor deficit, and 1 patient who developed motor deficit with loss of motor function of one upper extremity. One patient developed asymptomatic MRI changes and 6 experienced transient Lhermitt's syndrome.

In our series of 96 consecutive randomized patients, 10 patients (10.4\%) developed clinical symptoms and MRI changes consistent with radiation necrosis, after high-dose proton and photon radiation therapy to a portion of the 
brain. Although an underestimation of the true incidence of necrosis may be possible in this group of patients, the current series has some features that distinguish it from other reports in the literature.

Chordomas and chondrosarcomas of the base of the skull are extradural tumors that, during their local evolution, may abut or displace the normal brain instead of infiltrating the white matter as gliomas always do. This separation from the brain matter usually allows the differentiation of the area of late brain damage from the tumor site.

Although specific dose-response data for diffuse white matter changes are unavailable, postradiation necrosis, which has been described at $45 \mathrm{~Gy}$, is usually not seen when doses of $<60$ Gy are given with conventional fractionation $(5,36)$. In our series, all the patients received prescribed doses of 66.6 and $72 \mathrm{CGE}$, at 1.8 CGE per fraction, 5 treatments per week. However, these doses were generally conformed to the tumor, and relatively small volumes of the surrounding healthy brain received high doses. Indeed, this study shows that necrosis can occur in patients in whom $<10 \mathrm{cc}$ of healthy brain parenchyma received higher than $50 \mathrm{CGE}$, as is shown by the data reported in Table 7 for the patients with damage and the Control Group. Nevertheless, as illustrated by the different theories, the possible pathogenesis of brain necrosis is a complex phenomena that may be induced by factors other than the direct irradiation of a large area of white matter to high doses. The inclusion of the network of microarteries in the high-dose volume, for example, may produce thickening and occlusion of these blood vessels followed by ischemia and necrosis.

In addition to the effort to define a possible correlation between dose and volume to predict TL damage, several other baseline parameters were considered. Most of these variables are tumor- or host-related factors that may, in some way, influence or modify the response to irradiation of the healthy tissues. Some produce distortion of the normal anatomy of the brain matter or of the normal blood flow (e.g., encasing of the large arteries by the tumor), or modify the environment of the healthy tissues (following more than one surgical procedure) and were supposed to have some statistically significant relevance on the occurrence of the damage. Despite the higher rates of TL damage related to age, tumor volume, number of surgical procedures prior to radiation therapy, and prescribed dose to the tumor, only gender was a significant predictor of damage ( $p=0.0155)$ using a univariate (log rank) test. In a stepwise Cox regression that included gender as a variable, no other baseline variable significantly improved the predictivity of TL damage. An extended database including more patients and, consequently, more cases with late side effects might probably help to demonstrate the predictivity of some of the variables on TL damage and a prospective study on their relevance may be necessary.

In conclusion, chordomas and chondrosarcomas of the base of the skull undergoing high-dose photon and proton irradiation may represent a good model for estimating late radiation effects due to their prolonged survival, without local progression of the tumor, in comparison to glioma patients. Five-year local recurrence-free survival has been reported, in fact, to be $95 \pm 4 \%$ and $62 \pm 9 \%$, respectively, for chondrosarcomas and chordomas (37). Current treatment techniques are specifically designed to reduce total dose and dose per fraction to the temporal lobe, by treating at least 2 separate portals per day directed to the tumor, but entering through different volumes of brain, and by incorporating not only lateral portals but superior, oblique, or posterior portals into the overall treatment plan.

\section{REFERENCES}

1. Catton, C.; O’Sullivan, B.; Bell, R.; Laperriere, N.; Cummings, B.; Fornasier, V.; Wunder, J. Chordoma: long-term follow-up after radical photon irradiation. Radiother. Oncol. 41:67-70; 1996.

2. Emami, B.; Lyman, J.; Brown, A.; Coia, L.; Goitein, M.; Munzenrider, J. E.; Shank, B.; Solin, L. J.; Wesson, M. Tolerance of normal tissue to therapeutic irradiation. Int. J. Radiat. Oncol. Biol. Phys. 15:109-122; 1991.

3. Kramer, S. The Hazards of therapeutic irradiation of the central nervous system. Clin. Neurol. 15:301-318; 1980.

4. Lee, Y. Y.; Navert. C.; Glass, P. Treatment-related white matter changes in cancer patients. Cancer 57:1473-1482; 1986.

5. Sheline, G. E.; Wara, W. M.; Smith, V. Therapeutic irradiation and brain injury. Int. J. Radiat. Oncol. Biol. Phys. 6:1215$1228 ; 1980$.

6. Marks, J. E.; Baglan, R. J.; Prassad, S. C.; Blank, W. F. Cerebral radionecrosis: incidence and risk in relation to dose, time, fractionation and volume. Int. J. Radiat. Oncol. Biol. Phys. 7:243-252; 1981.

7. Urano, M.; Verhey, L.; Goitein, M.; Tepper, J.; Suit, H.; Mendiondo, O.; Gragoudas, E.; Koehler, A. Relative biolog- ical effectiveness of modulated proton beams in various murine tissues. Int. J. Radiat. Oncol. Biol. Phys. 10:509-514; 1984.

8. Raju, M.; Bain, E.; Carpenter, S.; Cox, R.; Robertson, J. A heavy particle comparative study Part II: cell survival vs. depth. Br. J. Radiol. 51:704-711; 1978.

9. Goitein, M.; Abrams, M. Multi-dimensional treatment planning: I. Delineation of anatomy. Int. J. Radiat. Oncol. Biol. Phys. 9:777-787; 1983.

10. Goitein, M.; Abrams, M.; Rowell, D.; Pollari, H.; Wiles, J. Multi-dimensional treatment planning: II. Beam's eye-view, back projection, and projection through CT sections. Int. J. Radiat. Oncol. Biol. Phys. 9:789-797; 1983.

11. Goitein, M. Compensation for inhomogeneities in charged particle radiotherapy using computed tomography. Int. J. Radiat. Oncol. Biol. Phys. 4:499-508; 1978.

12. Urie, M.; Goitein, M.; Wagner, M. Compensating for heterogeneities in proton radiation therapy. Phys. Med. Biol. 29: 553-566; 1984.

13. Verhey, L.; Goitein, M.; McNulty, P.; Munzenrider, J.; Suit, H. Precise positioning of patients for radiation therapy. Int. J. Radiat. Oncol. Biol. Phys. 8:289-294; 1982. 
14. Schultheiss, T. E.; Kun, L. E.; Ang, K. K.; Stephens, L. C. Radiation response of the central nervous system. Int. J. Radiat. Oncol. Biol. Phys. 31:1093-1112; 1995.

15. Burger, P. C.; Mahaley, M. S.; Duka, L.; Vogel, F. The morphologic effects of radiation administered therapeutically for intracranial gliomas. Cancer 44:1256-1272; 1979.

16. Conomy, J. P.; Kellermeyer, R. W. Delayed cerebrovascular consequences of therapeutic radiation. Cancer 26:1702-1708; 1975.

17. Courville, C. B.; Myers, R. O. The process of demyelination in the central nervous system. II. Mechanisms of demyelination of the cerebral centrum incident to X-radiation. J. Neuropathol. Exp. Neurol. 17:158-181; 1958.

18. De Rutter, J.; van Putten, L. M. Measurements of blood flow in the mouse tail after irradiation. Radiat. Res. 61:427-438; 1975.

19. Hopewell, J. W.; Wright, E. A. The nature of latent cerebral irradiation damage and its modification by hypertension. Br. J. Radiol. 43:161-167; 1970.

20. Hopewell, J. W. The late vascular effects of irradiation. Br. J. Radiol. 47:157-158; 1974.

21. Wright, T. L.; Bresnan, M. J. Radiation-induced cerebrovascular disease in children. Neurology 26:540-543; 1976.

22. Zeman, W. Disturbances of nucleic acid metabolism preeceding delayed radionecrosis of nervous tissue. Proc. Natl. Acad. Sci. USA 50:626-630; 1963.

23. Zeman, W.; Samorajski, T. Effect of irradiation on the nervous system. In: Berdjis, C. C., ed. Pathology of irradiation. Baltimore: Williams and Wilkins; 1971:213-277.

24. Crompton, M. R.; Layton, D. D. Delayed radionecrosis of brain following therapeutic X-radiation of the pituitary. Brain 84:85-101; 1961.

25. Thames, H. D.; Withers, H. R.; Peters, L. J.; Fletcher, G. H. Changes in early and late radiation responses with altered fractionation: Implications for dose-survival relationships. Int. J. Radiat. Oncol. Biol. Phys. 8:219-226; 1982.

26. Schultheiss, T. E.; Orton, C. G.; Peck, R. A. Models in radiotherapy: Volume effects. Med. Phys. 10:410-415; 1983.

27. Lee, A. W. M.; Ng, S. H.; Ho, J. H. C.; Tse, V. K. C.; Poon, Y. F.; Tse, C. C. H.; Au, G. K. H.; O, S. K.; Lau, W. H.; Foo, W. W. L. Clinical diagnosis of late temporal lobe necrosis following radiation therapy for nasopharyngeal carcinoma. Cancer 61:1535-1542; 1988.
28. Safadari, G. H.; Fuentes, J. M.; Dubois, J. B.; Alizerai, M.; Castan, P.; Viahovitch, B. Radiation necrosis of the brain. Time of onset and incidence related to total dose and fractionation of radiation. Neuroradiology 27:44-47; 1985.

29. Constine, L. S.; Konski, A.; Ekholm, S.; McDonald, S.; Rubin, P. Adverse effects of brain irradiation correlated with MR and CT imaging. Int. J. Radiat. Oncol. Biol. Phys. 15:319330; 1988.

30. Curran, W. J.; Hecht-Leavitt, C.; Schut, L.; Zimmerman, R. A.; Nelson, D. Magnetic resonance imaging of cranial radiation lesions. Int. J. Radiat. Oncol. Biol. Phys. 13:10931098; 1987.

31. Dooms, G. C.; Hecht, S.; Brant-Zawadzki, M.; Berthiaume, Y.; Norman, D.; Newton, T. H. Brain radiation lesions. MR imaging. Radiol. 158:149-155; 1986.

32. Tsuruda, J. S.; Kortman, K. E.; Bradley, W. G. Radiation effects on cerebral white matter: MR evaluations. AJNR 8:431-437; 1987.

33. Urie, M.; Fullerton, B.; Tatsuzaki, H.; Birnbaum, S.; Suit, H.; Phil, D.; Convery, K.; Skates, S.; Goitein, M. A dose response analysis of injury to cranial nerves and/or nuclei following proton beam radiation therapy. Int. J. Radiat. Oncol. Biol. Phys. 23:27-39; 1992.

34. Debus, J.; Hug, E. B.; Munzenrider, J. E.; Liebsch, N. J.; O'Farrell, D.; Efird, J.; Daly, W.; Suit, H. Brainstem tolerance to conformal radiotherapy of skull base tumors. (Abstr.) Int. J. Radiat. Oncol. Biol. Phys. 39(Suppl.):272; 1997.

35. Liu, M. C. C.; Munzenrider, J. E.; Finkelstein, D.; Liebsch, N.; Adams, J.; Hug, E. B. Radiation tolerance of the cervical spinal cord: incidence and dose-time relationship of symptomatic and asymptomatic late effects following high dose irradiation of paraspinal tumors. (Abstr.) Int. J. Radiat. Oncol. Biol. Phys. 39(Suppl.):273; 1997.

36. Kramer, S.; Southard, M. E.; Mansfield, C. M. Radiation effect and tolerance of the central nervous system. Front. Rad. Ther. Oncol. 6:332-345; 1972.

37. Munzenrider, J. E.; Liebsch, N. J.; Efird, J. T. Chordoma and chondrosarcoma of skull base: treatment with fractionated X-ray and proton radiotherapy. In: Johnson, J. T.; Didolkar, M. S., eds. Head and neck cancer. Vol. III. :Elsevier Science: 1993:649-654. 